\title{
Association between genetic variants and esophageal cancer risk
}

\author{
Chenli Yue ${ }^{1,2, *}$, Miao $\mathrm{Li}^{3, *}$, Chenxing $\mathrm{Da}^{4}$, Hongtao Meng ${ }^{5}$, Shaomin $\mathrm{Lv}^{2}$ and Xinhan \\ Zhao $^{1}$ \\ ${ }^{1}$ Department of Internal Medicine Oncology, The First Affiliated Hospital of Xi'an Jiaotong University, Xi'an, Shaanxi 710061, \\ China \\ ${ }^{2}$ Department of Respiratory Medicine, Shaanxi Provincial Crops Hospital of Chinese People's Armed Police Force, Xi'an, \\ Shaanxi 710054, China \\ ${ }^{3}$ Department of Internal Medicine Oncology, The Fifth People's Hospital of Qinghai Province, Xining, Qinghai 810007, China \\ ${ }^{4}$ Department of Gastroenterology, Shaanxi Provincial Crops Hospital of Chinese People's Armed Police Force, Xi'an, Shaanxi \\ 710054, China \\ ${ }^{5}$ Medical Department, Shaanxi Provincial Crops Hospital of Chinese People's Armed Police Force, Xi'an, Shaanxi 710054, \\ China \\ *These authors have contributed equally to this work
}

Correspondence to: Xinhan Zhao, email: zhaoxinhanprof@163.com

Keywords: esophageal cancer, genetic polymorphism, NAFl, han chinese, case-control

Received: October 27, $2016 \quad$ Accepted: February 17, $2017 \quad$ Published: April 10, 2017

Copyright: Yue et al. This is an open-access article distributed under the terms of the Creative Commons Attribution License 3.0 (CC BY 3.0), which permits unrestricted use, distribution, and reproduction in any medium, provided the original author and source are credited.

\section{ABSTRACT}

We investigated whether single nucleotide polymorphisms (SNPs) in the nuclear assembly factor 1 (NAF1) and TNFAIP3-interacting protein 1 (TNIP1) gene were associated with susceptibility to esophageal cancer in a Chinese Han population. Five SNPs were genotyped and their relationship with esophageal cancer risk was analyzed in a sample of 386 esophageal cancer patients and 495 unrelated healthy controls recruited from the First Affiliated Hospital of Xi'an Jiaotong University. Patients with the AG genotype of rs2320615 were at lower risk of developing esophageal cancer than those with the GG genotype (adjusted odds ratio [OR] $=0.64,95 \%$ confidence interval $[\mathrm{CI}]=0.46-0.90, P=0.009)$. The rs2320615 SNP was found to be associated with a decreased the risk of esophageal cancer in the dominant model (adjusted OR = $0.70,95 \% \mathrm{CI}=0.51-0.96, P=0.026)$. These results provide the first evidence that the rs2320615 in NAF1 was associated with reduced risk of esophageal cancer. Further studies with larger samples are warranted to confirm our findings.

\section{INTRODUCTION}

Esophageal cancer is the eighth most common cancer and the sixth leading cause of cancer-related mortality worldwide because of its extremely aggressive nature and the poor survival rate of affected patients $[1$, 2]. The risk of esophageal cancer has been associated with various environmental and genetic factors, as well as their interactions. Epidemiological evidence indicates that the most important environmental risk factors for esophageal cancer development include cigarette smoking, alcohol drinking, malnutrition, inadequate intake of fruits and fresh vegetables, and frequent consumption of pickled vegetables $[3,4]$. However, not all people exposed to these hazards eventually suffer from esophageal cancer. Recent studies have suggested the importance of genetic polymorphisms in the carcinogenesis and development of esophageal cancer $[5,6]$.

Previous studies identified the nuclear-assembly factor 1 (NAF1) protein is an essential H/ACA assembly factor, which might have a central role in coupling H/ACA snoRNP assembly interact with the carboxy terminal domain (CTD) of RNA polymerase (pol) II, and could facilitate recruitment and binding of the $\mathrm{H} / \mathrm{ACA}$ core proteins to the 
Table 1: Characteristics of esophageal cancer cases and healthy controls

\begin{tabular}{|c|c|c|c|}
\hline Variable & Case N (\%) & Control N (\%) & $P$ \\
\hline Total & 386 & 495 & \\
\hline Gender & & & $<0.001$ \\
\hline Male & 308 (79.8) & $180(36.4)$ & \\
\hline Female & $78(20.2)$ & $315(63.6)$ & \\
\hline Age, & & & $<0.001$ \\
\hline yrs $($ Mean \pm SD) & $60.9 \pm 9.0$ & $54.5 \pm 9.4$ & \\
\hline
\end{tabular}

$P$ values were calculated with Pearson's $\chi^{2}$ test (gender) and Welch's t test (age).

$P<0.05$ indicates statistical significance.

nascent snoRNA sequences $[7,8]$. In addition, a genomewide meta-analysis found that one SNP (rs7675998) in $N A F 1$ was associated with telomere length $\left(P=4.35 \times 10^{-16}\right)$ [9]. Rs2320615 was reported to be the best surrogates for rs7675998 (pairwise $r^{2}=0.89$ ) [10] and which was found to be associated with longer TL $\left(\mathrm{P}\right.$-trend $\left.=3.3 \times 10^{-4}\right)[11]$. Interestingly, short telomere lengths have been associated with esophageal carcinogenesis [12].

TNIP1 (TNF $\alpha$-induced protein 3-interacting protein 1), alternatively called $A B I N-1$ (A20-binding inhibitor of $\mathrm{NF}-\kappa \mathrm{B}$ activation) or Naf1 (Nef-associated factor 1). TNIP1 is a human cellular protein initially identified as interacting with the HIV proteins nef [13] and matrix [14]. It has been reported that TNIP1 are associated with some diseases, such as leukemia-lymphoma [15], systemic lupus erythematosus [16-18], psoriatic arthritis [19], systemic sclerosis [20, 21], asthma [22], and gastric carcinoma [23]. A previous study revealed that TNIP1 inhibited the activation of nuclear factor kappa-B (NF- $\mathrm{B})$ [24], and another study demonstrated that blocking the NF- $\mathrm{BB}$ signaling pathway inhibited esophageal cancer proliferation and metastasis [25].

Given the importance of telomere length and the NF- $\kappa \mathrm{B}$ signaling pathway in the development and maintenance of esophageal cancer, we hypothesized genetic polymorphisms in NAF1 and TNIP1 may influence esophageal cancer susceptibility. To test this hypothesis, we designed a case-control study including 386 esophageal cancer patients and 495 healthy controls to investigate the potential associations between SNPs and the risk of esophageal cancer in a Han Chinese population.

\section{RESULTS}

The basic characteristics of the cases and controls included in this study are summarized in Table 1 . In total, 386 esophageal cancer patients (308 males and 78 females) with a mean age of $60.9( \pm 9.0)$ years and 495 healthy controls (180 males and 315 females) with a mean age of $54.5( \pm 9.4)$ years were enrolled in our study. The age and gender distributions differed significantly between the cases and healthy controls $(P<0.001)$. To eliminate any residual confounding effects, we adjusted for the variables of age and gender in the subsequent multivariable unconditional logistic regression analysis.

The five SNPs (rs2320615, rs3792792, rs4958881, rs7708392, and rs10036748) were successfully genotyped in the esophageal cancer cases and healthy controls. The average SNP call rate was $98.3 \%$ in cases and controls. The sequences of primers for each SNP polymerase chain reaction $(\mathrm{PCR})$ and single base extension reaction are listed in Table 2. The minor allele frequencies for the five SNPs in the patient samples and normal controls are shown in Table 3 . We used a $\chi^{2}$ test to compare the differences in the frequency distributions of alleles between cases and controls, but no significant associations between the alleles of the five SNPs were detected. One SNP (rs4958881) was excluded from further analyses because it deviated from Hardy-Weinberg equilibrium in controls $(P<0.001)$.

The results of genetic model analyses are shown in Table 4. The AG genotype of rs2320615 was associated with significantly lower risk of esophageal cancer than the GG genotype, both before and after adjustment for age and gender $(\mathrm{OR}=0.67,95 \% \mathrm{CI}$ : $0.50-0.90, P=0.008$; adjusted $\mathrm{OR}=0.64,95 \% \mathrm{CI}: 0.46-0.90, P=0.009$, respectively). Furthermore, the SNP (rs2320615) was significantly associated with esophageal cancer risk under the dominant model after adjustment for age and gender (adjusted OR $=0.70,95 \% \mathrm{CI}: 0.51-0.96, P=0.026$ ). However, no significant association was found between TNIP1 polymorphisms and esophageal cancer risk.

As shown in Figure 1, we conducted linkage disequilibrium analysis for the four SNPs, and one linkage disequilibrium block consisted of two SNPs (rs7708392 and rs10036748) which exhibited statistically significant linkage $\left(r^{2}=0.98\right)$.

\section{DISCUSSION}

This case-control study was designed to investigate whether genetic variants of NAF1 and TNIP1 were associated with the risk of esophageal cancer in the Han Chinese population. Our data demonstrated that the rs2320615 in NAF1 was associated with significantly reduced risk of esophageal cancer. 
Table 2: Sequences of oligonucleotide primers used to analyze $N A F 1$ polymorphisms

\begin{tabular}{|c|c|c|c|}
\hline SNP-ID & 1st-PCRP & 2nd-PCRP & UEP \\
\hline rs2320615 & $\begin{array}{c}\text { ACGTTGGATGACCAATTTAAC } \\
\text { AAGACAGC }\end{array}$ & $\begin{array}{c}\text { ACGTTGGATGAGGCAG } \\
\text { AGACATTCCATTTG }\end{array}$ & CCATTTGAAAAGAAATAATTCTACT \\
\hline rs3792792 & $\begin{array}{c}\text { ACGTTGGATGCTCAGATCAGT } \\
\text { TCACTCCTC }\end{array}$ & $\begin{array}{c}\text { ACGTTGGATGATGGCA } \\
\text { GCTGTTACGGCCAC }\end{array}$ & ccctTTACGGCCACCACCAAGCATG \\
\hline rs4958881 & $\begin{array}{c}\text { ACGTTGGATGCACAAATATGT } \\
\text { GGACAGTTT }\end{array}$ & $\begin{array}{l}\text { ACGTTGGATGTGCAAT } \\
\text { TCCACCCAAGGATG }\end{array}$ & GGATGAAAGGAAGTGAGA \\
\hline rs7708392 & $\begin{array}{c}\text { ACGTTGGATGAGGCCAACTGG } \\
\text { TCAATTCTC }\end{array}$ & $\begin{array}{c}\text { ACGTTGGATGGGGTCT } \\
\text { CTTCTGGAACTTAG }\end{array}$ & ggggaTGGAACTTAGTAGACTAGTCA \\
\hline rs 10036748 & $\begin{array}{c}\text { ACGTTGGATGGCAAAGCAGC } \\
\text { CCСTTTTTTC }\end{array}$ & $\begin{array}{l}\text { ACGTTGGATGCTTTCAT } \\
\text { AGCATGATACACG }\end{array}$ & ACGTATGAGAAAAATAAAATAGTAA \\
\hline
\end{tabular}

SNP: Single nucleotide polymorphism; PCRP: Polymerase chain reaction primer; UEP: unique base extension primer Sequences are written in the 5 ' $\rightarrow 3$ ' (left to right) orientation.

Table 3: Allele frequencies in cases and controls and odds ratio estimates for esophageal cancer

\begin{tabular}{|c|c|c|c|c|c|c|c|c|c|c|c|c|}
\hline \multirow{2}{*}{ SNP-ID } & \multirow{2}{*}{ Gene } & \multirow{2}{*}{ Chr } & \multirow{2}{*}{ Band } & \multirow{2}{*}{ Position } & \multirow{2}{*}{ Role } & \multirow{2}{*}{$\begin{array}{c}\text { Alleles } \\
\text { (A/B) }\end{array}$} & \multicolumn{2}{|c|}{ MAF } & \multirow{2}{*}{ HWE } & \multirow{2}{*}{ OR } & \multirow{2}{*}{$\begin{array}{c}95 \% \\
\text { CI }\end{array}$} & \multirow{2}{*}{$\boldsymbol{P}$} \\
\hline & & & & & & & Case & Control & & & & \\
\hline rs2320615 & $N A F 1$ & 4 & $4 q 32.2$ & 164069949 & Intron & $\mathrm{A} / \mathrm{G}$ & 0.178 & 0.210 & 0.344 & 0.81 & $\begin{array}{c}0.64- \\
1.03\end{array}$ & 0.090 \\
\hline rs3792792 & TNIP1 & 5 & $5 q 33.1$ & 150440506 & Intron & $\mathrm{C} / \mathrm{T}$ & 0.078 & 0.063 & 0.711 & 1.26 & $\begin{array}{c}0.87- \\
1.82\end{array}$ & 0.216 \\
\hline rs4958881 & TNIP1 & 5 & $5 q 33.1$ & 150450236 & Intron & $\mathrm{C} / \mathrm{T}$ & 0.123 & 0.092 & $<0.001$ & 1.39 & $\begin{array}{c}1.02- \\
1.89\end{array}$ & 0.035 \\
\hline rs7708392 & TNIP1 & 5 & $5 q 33.1$ & 150457485 & Intron & $\mathrm{G} / \mathrm{C}$ & 0.231 & 0.224 & 0.438 & 1.04 & $\begin{array}{c}0.83- \\
1.30\end{array}$ & 0.753 \\
\hline rs10036748 & TNIP1 & 5 & $5 q 33.1$ & 150458146 & Intron & $\mathrm{C} / \mathrm{T}$ & 0.229 & 0.226 & 0.306 & 1.02 & $\begin{array}{l}0.81- \\
1.28\end{array}$ & 0.864 \\
\hline
\end{tabular}

SNP: Single nucleotide polymorphism; Chr: Chromosome; MAF: Minor allele frequency; HWE: Hardy-Weinberg equilibrium; OR: Odds ratio; 95\% CI: 95\% Confidence interval.

$P$ values were calculated with the Chi-Square test.

$P<0.05$ indicates statistical significance.

$N A F 1$ encodes a protein important for the assembly of H/ACA human telomerase RNA [8]. This chaperone protein is involved in the formation and activity of telomerase, and a previous study indicated that NAF1 polymorphism (rs7675998) is associated with mean telomere length [9]. Interestingly, short leukocyte telomere lengths are associated with significantly increased risk of developing esophageal cancer [12]. Our results suggested that NAF1 polymorphisms are associated with the risk of esophageal cancer. However, it remains unclear whether these $N A F 1$ polymorphisms affect telomere length by affecting specific protein synthesis and function, and ultimately the susceptibility to esophageal cancer. This assumption will be tested in future gene functional experiments.
Our results demonstrated that the genotype AG of rs2320615 in NAF1 was associated with a significantly reduced risk of esophageal cancer. A study found that the rs2320615 is associated with longer telomere length [11]. Because we did not explore the association of the SNP with telomere length and the association between telomere length and esophageal cancer risk in this study, it is unclear whether these SNPs affect telomere length, which in turn affects the risk of esophageal cancer. It is possible that polymorphisms can affect the expression of genes and thus render individuals susceptible to esophageal cancer. We will confirm our results and speculation in future studies. 
Table 4: Genetic model analyses of the associations between the SNPs and esophageal cancer susceptibility

\begin{tabular}{|c|c|c|c|c|c|c|c|c|c|c|}
\hline \multirow{2}{*}{ SNP-ID } & \multirow{2}{*}{ Model } & \multirow{2}{*}{ Genotype } & \multirow{2}{*}{ Case (N) } & \multirow{2}{*}{$\begin{array}{c}\text { Control } \\
(\mathrm{N})\end{array}$} & \multicolumn{3}{|c|}{ Without adjustment } & \multicolumn{3}{|c|}{ With adjustment } \\
\hline & & & & & OR & $95 \% \mathrm{CI}$ & $P$ & OR & $95 \% \mathrm{CI}$ & $P$ \\
\hline \multirow[t]{8}{*}{ rs2320615 } & Co-dominant & GG & 263 & 305 & 1.00 & & & 1.00 & & \\
\hline & & $\mathrm{AG}$ & 99 & 172 & 0.67 & $0.50-0.90$ & 0.008 & 0.64 & $0.46-0.90$ & 0.009 \\
\hline & & AA & 18 & 18 & 1.16 & $0.59-2.28$ & 0.667 & 1.27 & $0.58-2.78$ & 0.544 \\
\hline & Dominant & GG & 263 & 305 & 1.00 & & & 1.00 & & \\
\hline & & AG-AA & 117 & 190 & 0.71 & $0.54-0.95$ & 0.020 & 0.7 & $0.51-0.96$ & 0.026 \\
\hline & Recessive & GG-AG & 362 & 477 & 1.00 & & & 1.00 & & \\
\hline & & AA & 18 & 18 & 1.32 & $0.68-2.57$ & 0.418 & 1.47 & $0.68-3.19$ & 0.330 \\
\hline & Additive & --- & --- & --- & 0.81 & $0.64-1.04$ & 0.093 & 0.81 & $0.62-1.06$ & 0.120 \\
\hline \multirow[t]{8}{*}{ rs3792792 } & Co-dominant & $\mathrm{TT}$ & 328 & 434 & 1.00 & & & 1.00 & & \\
\hline & & $\mathrm{CT}$ & 56 & 60 & 1.24 & $0.84-1.83$ & 0.291 & 1.37 & $0.88-2.13$ & 0.169 \\
\hline & & $\mathrm{CC}$ & 2 & 1 & 2.65 & $0.24-29.31$ & 0.428 & 1.79 & $\begin{array}{l}0.16- \\
20.09\end{array}$ & 0.636 \\
\hline & Dominant & $\mathrm{TT}$ & 328 & 434 & 1.00 & & & 1.00 & & \\
\hline & & CT-CC & 58 & 61 & 1.26 & $0.85-1.85$ & 0.245 & 1.38 & $0.89-2.14$ & 0.153 \\
\hline & Recessive & TT-CT & 384 & 494 & 1.00 & & & 1.00 & & \\
\hline & & $\mathrm{CC}$ & 2 & 1 & 2.57 & $0.23-28.48$ & 0.441 & 1.72 & $\begin{array}{l}0.15- \\
19.26\end{array}$ & 0.660 \\
\hline & Additive & --- & --- & --- & 1.27 & $0.87-1.84$ & 0.212 & 1.36 & $0.90-2.08$ & 0.149 \\
\hline \multirow[t]{8}{*}{ rs7708392 } & Co-dominant & $\mathrm{CC}$ & 231 & 301 & 1.00 & & & 1.00 & & \\
\hline & & $\mathrm{GC}$ & 132 & 166 & 1.04 & $0.78-1.38$ & 0.808 & 1.05 & $0.76-1.44$ & 0.790 \\
\hline & & GG & 23 & 28 & 1.07 & $0.60-1.91$ & 0.818 & 1.22 & $0.63-2.36$ & 0.553 \\
\hline & Dominant & $\mathrm{CC}$ & 231 & 301 & 1.00 & & & 1.00 & & \\
\hline & & GC-GG & 155 & 194 & 1.04 & $0.79-1.37$ & 0.772 & 1.07 & $0.79-1.45$ & 0.673 \\
\hline & Recessive & CC-GC & 363 & 467 & 1.00 & & & 1.00 & & \\
\hline & & GG & 23 & 28 & 1.06 & $0.60-1.87$ & 0.849 & 1.2 & $0.63-2.30$ & 0.578 \\
\hline & Additive & --- & --- & --- & 1.04 & $0.83-1.29$ & 0.757 & 1.07 & $0.84-1.38$ & 0.577 \\
\hline \multirow[t]{8}{*}{ rs 10036748} & Co-dominant & $\mathrm{TT}$ & 230 & 300 & 1.00 & & & 1.00 & & \\
\hline & & $\mathrm{CT}$ & 132 & 165 & 1.04 & $0.78-1.39$ & 0.771 & 1.06 & $0.77-1.47$ & 0.707 \\
\hline & & $\mathrm{CC}$ & 22 & 29 & 0.99 & $0.55-1.77$ & 0.972 & 1.11 & $0.57-2.15$ & 0.763 \\
\hline & Dominant & $\mathrm{TT}$ & 230 & 300 & 1.00 & & & 1.00 & & \\
\hline & & CT-CC & 154 & 194 & 1.04 & $0.79-1.36$ & 0.802 & 1.07 & $0.79-1.46$ & 0.667 \\
\hline & Recessive & TT-CT & 362 & 465 & 1.00 & & & 1.00 & & \\
\hline & & $\mathrm{CC}$ & 22 & 29 & 0.97 & $0.55-1.73$ & 0.929 & 1.08 & $0.56-2.08$ & 0.811 \\
\hline & Additive & --- & --- & --- & 1.02 & $0.82-1.27$ & 0.866 & 1.06 & $0.82-1.36$ & 0.658 \\
\hline
\end{tabular}

SNP: Single nucleotide polymorphism; OR: Odds ratio; 95\% CI: 95\% Confidence interval

The logistic regression analysis was adjusted for age and gender.

$P$ values were calculated with the Wald test.

$P<0.05$ indicates statistical significance. 
Two recent GWASs revealed that rs7708392 and rs10036748 were associated with the risk of systemic lupus erythematosus [16, 17]. A previous report also indicated that the $\mathrm{G}$ allele of rs7708392 and the $\mathrm{C}$ allele of rs 10036748 were associated with increased risk of gastric carcinoma, and that the haplotype CT (rs7708392-rs10036748) was associated with a reduced risk of gastric carcinoma [23]. In addition, a significantly decreased association was found between the allele $\mathrm{T}$ of rs10036748 and asthma risk [22]. Recently, the NF$\kappa \mathrm{B}$ signaling pathway was reported to be associated with tumorigenesis in esophageal cancer [25]. NF$\kappa \mathrm{B}$ is a ubiquitous transcription factor that involves in immunity and inflammation, regulates cell proliferation, apoptosis and migration, and is constitutively activated in a number of human cancers, including some esophageal cancers [26-28]. Previous studies have demonstrated that TNIP1 can inhibit NF- $\mathrm{B}$ activity $[29,30]$. However, no significant association between TNIP1 and esophageal cancer risk was found in the study.

There are some limitations to the present casecontrol study. First, the relatively small sample did not have sufficient statistical power to reflect the precise association between SNPs and the susceptibility to esophageal cancer. Second, many other risk factors (e.g., smoking, alcohol drinking) were not included due to a lack of corresponding clinical information. Third, biological function analyses were not conducted and deserve further study.

In conclusion, the current study has identified that rs2320615 in the $N A F 1$ was associated with the risk of esophageal cancer in the Han Chinese population. These findings provide a theoretical foundation for further research (with a large sample) into the association between NAF1 and TNIP1 and esophageal cancer risk in other populations.

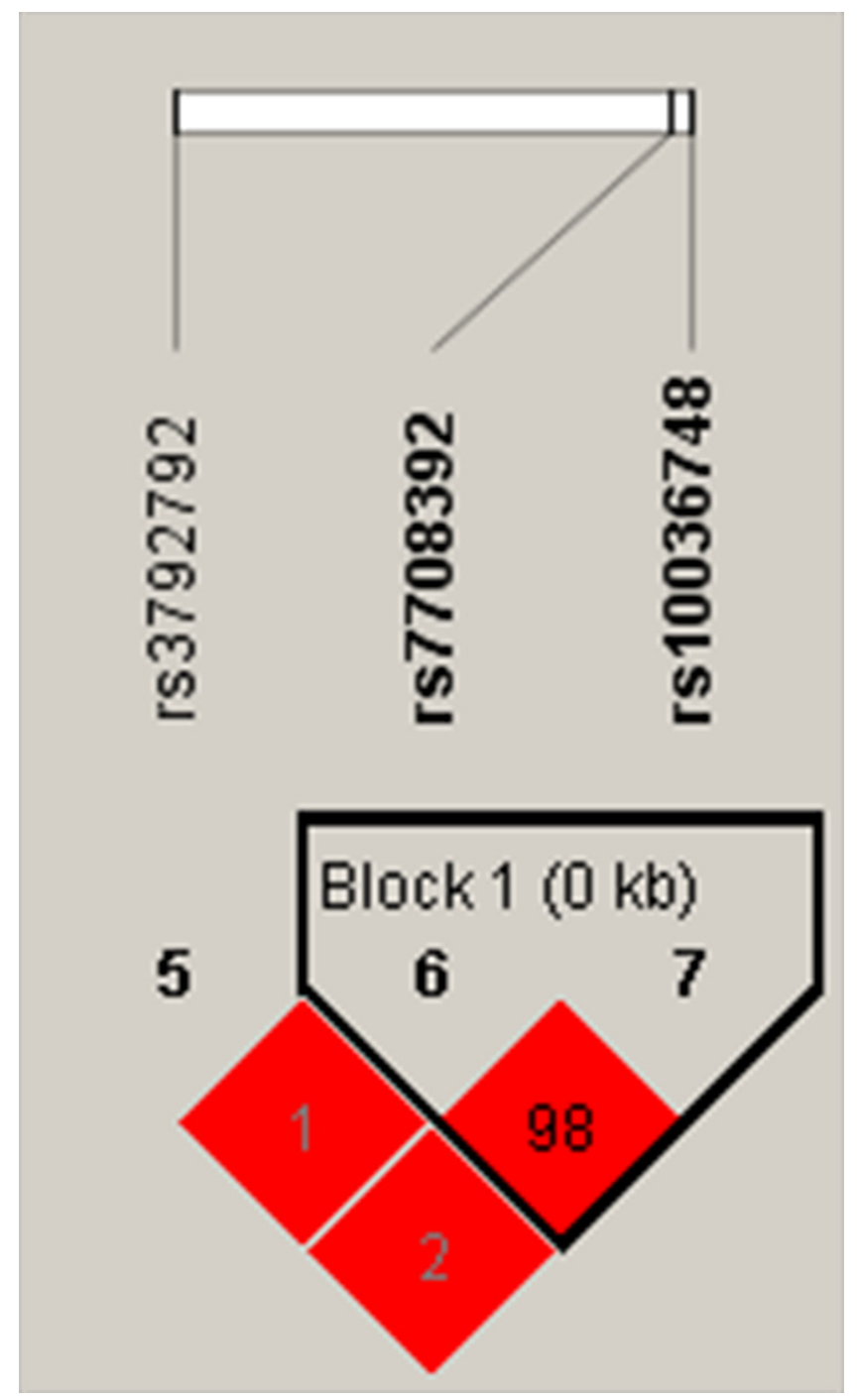

Figure 1: Haplotype block map for the three SNPs in the TNIP1 gene. The LD between two SNPs is expressed as a standardized D' value (red schemes). 


\section{MATERIALS AND METHODS}

\section{Study subjects}

We recruited 386 patients who were diagnosed with esophageal cancer at the First Affiliated Hospital of Xi' an Jiaotong University between July 2014 and October 2015. The 495 controls without histories of cancer or other major diseases were randomly selected from the health evaluation center at the same hospital during the same time period. All participants were of ethnic Han origin, and their ancestors had lived in the region for at least three generations. Patients who previously had cancer, radiotherapy or chemotherapy were excluded. All cases were recruited without any restrictions regarding age, sex, or disease stage. In addition, each subject was personally questioned by trained interviewers, who used a pre-tested questionnaire to obtain basic information, including demographic data (e.g., age, sex) and some clinical information.

This study was approved by the Ethical Committee of the First Affiliated Hospital of Xi'an Jiaotong University, and complied with the World Medical Association Declaration of Helsinki. All individuals gave written informed consent to be included in the study.

\section{DNA extraction}

A vacutainer was used to collect a peripheral venous blood sample $(5 \mathrm{~mL})$ fromeach study subject, and the sample was transferred to a tube containing ethylenediamine tetra-acetic acid. All blood samples were stored at $-20^{\circ} \mathrm{C}$ until DNA extraction. Genomic DNA was isolated from whole blood with the GoldMag-Mini Whole Blood Genomic DNA Purification Kit according to the manufacturer's protocol (GoldMag. Co. Ltd., Xi'an, China). The concentration of the isolated DNA was measured with a spectrophotometer (NanoDrop 2000; Thermo Fisher Scientific, Waltham, MA, USA) at wavelengths of A260 and A280 nm. The DNA was diluted with QIAgility to a final concentration of $20 \mathrm{ng} / \mu \mathrm{l}$.

\section{SNP selection and genotyping}

Five SNPs (rs2320615, rs3792792, rs4958881, rs7708392 and rs10036748) with had minor allele frequency $>5 \%$ in the HapMap of the Chinese Han Beijing population that have been reported to be associated with the risk of several diseases and cancers, including systemic lupus erythematosus [16-18], systemic sclerosis [21], asthma [22], and gastric carcinoma [23]. They were selected for further genotyping. Primers for the amplification process and single base extension reactions were designed with Sequenom Mass-ARRAY Assay Design 3.0 Software (Sequenom, San Diego, CA, USA). Genotyping of the SNPs was performed with the
Sequenom MassARRAY platform [31] (Sequenom, San Diego, CA, USA) according to the standard instructions recommended by the manufacturer. Sequenom Typer 4.0 software was used for data management and analyses.

\section{Statistical analysis}

For cases and controls, we analyzed the gender distribution using Pearson's $\chi^{2}$ test and the age distribution by Welch's $t$ test. We analyzed the genotype frequencies in the controls with Fisher's exact test to determine whether the five SNPs departed from Hardy-Weinberg equilibrium. The differences in the SNP allele and genotype distributions between patients and controls were evaluated with Chi-squared test/Fisher's exact tests. Genetic model analyses (Dominant, Recessive and Additive) were performed with PLINK software to assess the significance of the SNPs. The associations of the SNPs with the risk of esophageal cancer were estimated from the odds ratios (ORs) and 95\% confidence intervals (CIs), which were determined by unconditional logistic regression and adjusted for age and gender [32]. The $P$-values reported are two-sided, and values of $P<0.05$ were considered to be statistically significant. We used the Haploview software package (version 4.2) platform for analyses of pairwise linkage disequilibrium (LD) and haplotype structure [10]. All statistical analyses were performed with Microsoft Excel and SPSS 19.0 (SPSS, Chicago, IL, USA).

\section{ACKNOWLEDGMENTS}

We thank all authors for their contributions and support. Author Xinhan Zhao designed the study. Authors Chenli Yue and Miao Li analyzed the data and wrote the paper. Authors Chenxing Da, Hongtao Meng and Shaomin $\mathrm{Lv}$ performed the experiments. We are also grateful to all participants for providing blood samples.

\section{CONFLICTS OF INTEREST}

The authors declare that there are no conflicts of interest.

\section{REFERENCES}

1. Pennathur A, Gibson MK, Jobe BA, Luketich JD. Oesophageal carcinoma. Lancet. 2013; 381:400-412.

2. Zhang Y. Epidemiology of esophageal cancer. World journal of gastroenterology. 2013; 19:5598-5606.

3. Gao YT, McLaughlin JK, Blot WJ, Ji BT, Benichou J, Dai Q, Fraumeni JF Jr. Risk factors for esophageal cancer in Shanghai, China. I. Role of cigarette smoking and alcohol drinking. International journal of cancer. 1994; 58:192-196. 
4. Gao YT, McLaughlin JK, Gridley G, Blot WJ, Ji BT, Dai Q, Fraumeni JF Jr. Risk factors for esophageal cancer in Shanghai, China. II. Role of diet and nutrients. International journal of cancer. 1994; 58:197-202.

5. Hiyama T, Yoshihara M, Tanaka S, Chayama K. Genetic polymorphisms and esophageal cancer risk. International journal of cancer. 2007; 121:1643-1658.

6. Xing D, Tan W, Lin D. Genetic polymorphisms and susceptibility to esophageal cancer among Chinese population (review). Oncology reports. 2003; 10:1615-1623.

7. Richard $P$, Kiss $T$. Integrating snoRNP assembly with mRNA biogenesis. EMBO reports. 2006; 7:590-592.

8. Egan ED, Collins K. An enhanced H/ACA RNP assembly mechanism for human telomerase RNA. Molecular and cellular biology. 2012; 32:2428-2439.

9. Codd V, Nelson CP, Albrecht E, Mangino M, Deelen J, Buxton JL, Hottenga JJ, Fischer K, Esko T, Surakka I, Broer L, Nyholt DR, Mateo Leach I, et al. Identification of seven loci affecting mean telomere length and their association with disease. Nature genetics. 2013; 45:422427, 427e421-422.

10. Barrett JC, Fry B, Maller J, Daly MJ. Haploview: analysis and visualization of LD and haplotype maps. Bioinformatics. 2005; 21:263-265.

11. Pooley KA, Bojesen SE, Weischer M, Nielsen SF, Thompson D, Amin Al Olama A, Michailidou K, Tyrer JP, Benlloch S, Brown J, Audley T, Luben R, Khaw KT, et al. A genome-wide association scan (GWAS) for mean telomere length within the COGS project: identified loci show little association with hormone-related cancer risk. Human molecular genetics. 2013; 22:5056-5064.

12. Xing J, Ajani JA, Chen M, Izzo J, Lin J, Chen Z, Gu J, Wu $X$. Constitutive short telomere length of chromosome $17 \mathrm{p}$ and $12 q$ but not $11 q$ and $2 p$ is associated with an increased risk for esophageal cancer. Cancer prevention research. 2009; 2:459-465.

13. Fukushi M, Dixon J, Kimura T, Tsurutani N, Dixon MJ, Yamamoto N. Identification and cloning of a novel cellular protein Naf1, Nef-associated factor 1, that increases cell surface CD4 expression. FEBS letters. 1999; 442:83-88.

14. Gupta K, Ott D, Hope TJ, Siliciano RF, Boeke JD. A human nuclear shuttling protein that interacts with human immunodeficiency virus type 1 matrix is packaged into virions. Journal of virology. 2000; 74:11811-11824.

15. Shiote Y, Ouchida M, Jitsumori Y, Ogama Y, Matsuo Y, Ishimaru F, Tanimoto M, Shimizu K. Multiple splicing variants of Nafl/ABIN-1 transcripts and their alterations in hematopoietic tumors. International journal of molecular medicine. 2006; 18:917-923.

16. Han JW, Zheng HF, Cui Y, Sun LD, Ye DQ, Hu Z, Xu JH, Cai ZM, Huang W, Zhao GP, Xie HF, Fang H, Lu $\mathrm{QJ}$, et al. Genome-wide association study in a Chinese
Han population identifies nine new susceptibility loci for systemic lupus erythematosus. Nature genetics. 2009; 41:1234-1237.

17. Gateva V, Sandling JK, Hom G, Taylor KE, Chung SA, Sun X, Ortmann W, Kosoy R, Ferreira RC, Nordmark G, Gunnarsson I, Svenungsson E, Padyukov L, et al. A largescale replication study identifies TNIP1, PRDM1, JAZF1, UHRF1BP1 and IL10 as risk loci for systemic lupus erythematosus. Nature genetics. 2009; 41:1228-1233.

18. Kawasaki A, Ito S, Furukawa H, Hayashi T, Goto D, Matsumoto I, Kusaoi M, Ohashi J, Graham RR, Matsuta K, Behrens TW, Tohma S, Takasaki Y, et al. Association of TNFAIP3 interacting protein 1, TNIP1 with systemic lupus erythematosus in a Japanese population: a case-control association study. Arthritis research \& therapy. 2010; 12:R174.

19. Bowes J, Orozco G, Flynn E, Ho P, Brier R, Marzo-Ortega H, Coates L, McManus R, Ryan AW, Kane D, Korendowych E, McHugh N, FitzGerald O, et al. Confirmation of TNIP1 and IL23A as susceptibility loci for psoriatic arthritis. Annals of the rheumatic diseases. 2011; 70:1641-1644.

20. Allanore Y, Saad M, Dieude P, Avouac J, Distler JH, Amouyel P, Matucci-Cerinic M, Riemekasten G, Airo P, Melchers I, Hachulla E, Cusi D, Wichmann HE, et al. Genome-wide scan identifies TNIP1, PSORS1C1, and RHOB as novel risk loci for systemic sclerosis. PLoS genetics. 2011; 7:e1002091.

21. Bossini-Castillo L, Martin JE, Broen J, Simeon CP, Beretta L, Gorlova OY, Vonk MC, Ortego-Centeno N, Espinosa G, Carreira P, Garcia de la Pena P, Oreiro N, Roman-Ivorra JA, et al. Confirmation of TNIP1 but not RHOB and PSORS1C1 as systemic sclerosis risk factors in a large independent replication study. Annals of the rheumatic diseases. 2013; 72:602-607.

22. Li X, Ampleford EJ, Howard TD, Moore WC, Torgerson DG, Li H, Busse WW, Castro M, Erzurum SC, Israel E, Nicolae DL, Ober C, Wenzel SE, et al. Genomewide association studies of asthma indicate opposite immunopathogenesis direction from autoimmune diseases. The Journal of allergy and clinical immunology. 2012; 130:861-868 e867.

23. Liu Z, Shi Y, Na Y, Zhang Q, Cao S, Duan X, Zhang X, Yang H, Jin T, Li Y. Genetic polymorphisms in TNIP1 increase the risk of gastric carcinoma. Oncotarget. 2016; 7:40500-40507. doi: 10.18632/oncotarget.9637.

24. Gurevich I, Zhang C, Francis N, Aneskievich BJ. TNIP1, a retinoic acid receptor corepressor and A20-binding inhibitor of NF-kappaB, distributes to both nuclear and cytoplasmic locations. The journal of histochemistry and cytochemistry. 2011; 59:1101-1112.

25. Li B, Li YY, Tsao SW, Cheung AL. Targeting NF-kappaB signaling pathway suppresses tumor growth, angiogenesis, and metastasis of human esophageal cancer. Molecular cancer therapeutics. 2009; 8:2635-2644. 
26. Karin M. Nuclear factor-kappaB in cancer development and progression. Nature. 2006; 441:431-436.

27. Tian F, Zang WD, Hou WH, Liu HT, Xue LX. Nuclear factor-kB signaling pathway constitutively activated in esophageal squamous cell carcinoma cell lines and inhibition of growth of cells by small interfering RNA. Acta biochimica et biophysica Sinica. 2006; 38:318-326.

28. Konturek PC, Nikiforuk A, Kania J, Raithel M, Hahn EG, Muhldorfer S. Activation of NFkappaB represents the central event in the neoplastic progression associated with Barrett's esophagus: a possible link to the inflammation and overexpression of COX-2, PPARgamma and growth factors. Digestive diseases and sciences. 2004; 49:1075-1083.
29. Verstrepen L, Carpentier I, Verhelst K, Beyaert R. ABINs: A20 binding inhibitors of NF-kappa B and apoptosis signaling. Biochemical pharmacology. 2009; 78:105-114.

30. Heyninck K, Kreike MM, Beyaert R. Structure-function analysis of the A20-binding inhibitor of NF-kappa B activation, ABIN-1. FEBS letters. 2003; 536:135-140.

31. Gabriel S, Ziaugra L, Tabbaa D. SNP genotyping using the Sequenom MassARRAY iPLEX platform. Current protocols in human genetics. 2009; Chapter 2:Unit 212.

32. Bland JM, Altman DG. Statistics notes. The odds ratio. Bmj. 2000; 320:1468. 